\title{
VISITA DOMICILIAR A LONGEVOS: PERSPECTIVA DE PROFISSIONAIS DA SAÚDE DA FAMÍLIA
}

Cíntia Cristina Sulzbach; Universidade Federal de Santa Maria - UFSM; cintia.sulz@gmail.com; Loiva Beatriz Dallepiane; Universidade Federal de Santa Maria - UFSM; loiva.dallepiane@hotmail.com.

\section{RESUMO}

Introdução: A visita domiciliar é um dispositivo de cuidado imprescindível na saúde do idoso, sobretudo aos longevos, indivíduos com 80 anos ou mais. Este é o segmento populacional que mais tem crescido no Brasil, apresenta maior vulnerabilidade e está associada à dependência funcional. Objetivo: Analisar a percepção de profissionais de Saúde da Família acerca da realização de Visitas Domiciliares a idosos longevos. Métodos: Estudo qualitativo e exploratório com 10 profissionais, utilizando entrevista semi-estruturada, em Estratégias de Saúde da Família de Palmeira das Missões, RS. Realizou-se análise temática de conteúdo. O estudo foi aprovado pelo Comitê de Ética em Pesquisa da UFSM, parecer no 61829916.6.0000.5346. Resultados: Alguns profissionais possuem um turno da semana para a realização das visitas, muitas delas agendadas ou solicitadas por familiar ou outro profissional. Na atenção prestada aos longevos é realizada procedimentos, verificação do estado de saúde e avaliação do contexto social. Destacou-se a discussão dos casos e definição de prioridades com toda a equipe. O processo de envelhecimento, marcado pelo aumento de doenças crônicas, perdas funcionais, diminuição da socialização e pela fragilização, necessita de abordagens diferenciadas durantes as visitas domiciliares, o que não foi referido. Conclusão: Apesar de não se constituírem como porta de entrada, as visitas domiciliares facilitam o acesso dos longevos aos direitos e cuidados em saúde. A percepção dos profissionais de saúde é relevante para a qualificação do cuidado aos longevos e pode servir como ferramenta para a constituição e desenvolvimento de linhas de cuidado integrais.

Palavras-chave: Saúde do Idoso; Sistema Único de Saúde; Atenção Primária à Saúde 